\title{
¿Es cierta la regla de los 5 segundos? Contaminación de alimentos por microbiota ambiental
}

\author{
Daniel Prince Torregrosa \\ al374002@uji.es \\ Lucía Morán Lazcano \\ al374010@uji.es \\ Begonya Vicedo Jover \\ bvicedo@uji.es
}

\section{Resumen}

Introducción: En función de la conocida popularmente «regla de los cinco segundos» se decidió realizar un estudio experimental que comprobara la veracidad y la rigurosidad científica que sugiere el dicho popular. En este se advierte a la ciudadanía desde la infancia de lo poco higiénico que resulta recoger e ingerir alimentos que han caído al suelo, pero también se insinúa que dicha pieza de alimento se mantiene limpia si es recogida del suelo en un periodo determinado de tiempo, en concreto un periodo menor o igual a cinco segundos. El presente trabajo pretende simular la caída y recogida de alimentos del suelo, permaneciendo en este durante tiempos diferentes y en distintos tipos de suelo, con la intención de realizar un estudio microbiológico de la simulación.

Metodología: Para ello, se han tomado muestras en medio de cultivo sólido (Nutrient Agar) procedentes del suelo del laboratorio de microbiología y del pasillo general (suelo público) a 1 y 4 segundos después del contacto del medio con el suelo. Estos cultivos se han incubado durante 48 horas en estufa a $27^{\circ} \mathrm{C}$. Posteriormente se ha realizado el recuento total de las unidades formadoras de colonias así como un estudio de la variabilidad muestral.

Resultados: Los resultados obtenidos nos indican que existe una mayor carga microbiológica en aquellas muestras expuestas mayor tiempo a la superficie y en las que entraron en contacto con el suelo público. Además, en el primer segundo ya observamos contaminación y logramos distinguir colonias morfológicamente distintas entre ambos suelos.

Conclusiones: Por lo tanto, podemos afirmar que la «regla de los cinco segundos» no es cierta. Deducimos esto a causa de que se da una contaminación inmediata al contacto con las superficies, tanto en el microecosistema público como en el limpio, a pesar de hallar diferentes morfologías en las muestras.

Palabras clave: regla de los 5 segundos, microbiota de suelos, contaminación de alimentos. 


\section{Abstract}

Introduction: In accordance with the widely known "five second rule", an experimental study was conducted which tested the veracity and scientific rigour of this popular saying. Here, citizens are warned since childhood about how unhygienic it is to ingest food that has fallen on the floor, but it is also implied that this food remains safe if it is picked up from the floor in a determined period of time. In this case, less than or equal to five seconds. The present work attempts to simulate the action of dropping and collecting foods from the ground, remaining in contact with different floor surfaces for different time intervals, in order to carry out a microbiological study of the simulation.

Methods: To achieve this purpose, samples have been taken in solid culture medium (Nutrient Agar) from the soil of the microbiology laboratory and the general corridor (public floor) and 1 and 4 seconds after the contact of the medium with the soil. These cultures have been incubated for 48 hours in an culture stove at $27^{\circ} \mathrm{C}$. Subsequently, the total count of the Colony Forming Units as well as a study of the sample variability has been carried out.

Results: The results obtained prove that there is a greater microbiological load in those samples that were exposed for a longer time to the surface and in the ones that entered in contact with the public floor. Additionally, in the first second we already observe a degree of contamination and we can perceive morphologically different colonies between both floors.

Conclusion: Therefore, we can affirm that the "five second rule" is not true. We deduce this because there is an immediate contamination when the surfaces come in contact, both in the public microecosystem and in the clean one, in spite of finding different morphologies in the samples.

Keywords: five second rule, soil microbiota, food contamination.

\section{Introducción}

La regla de los cinco segundos (R5S) es una creencia popular que afirma que cualquier alimento que caiga en el suelo tiene un margen de 5 segundos antes de ser contaminado. Se escribió sobre ella hace 19 años en una colección de relatos, definiéndola así: "Si se deja caer comida en el suelo, no debe permanecer más de cinco segundos en este, pues tras cinco segundos se les permite a los gérmenes infestar la comida». (Kluck 2000).

En el 2003 la estudiante J. Clarke dirigió un estudio universitario (Pickle simer 2003) en el que demostró que el $70 \%$ de las mujeres y el $56 \%$ de hombres del estudio conocían y practicaban la R5S. Lo cual implica que posiblemente la mayoría de la población ingiere alimento que ha estado en contacto con superficies contaminadas durante cortos periodos de tiempo, pues creen que las piezas de comida permanecen limpias (sin adherencia de microorganismos) y, por tanto, corren el riesgo de sufrir una patología gastrointestinal, dependiendo de la carga microbiológica que tenga la superficie en la que ha estado en contacto. Por otro lado, otros trabajos demuestran que un simple roce con las superficies que están expuestas al contexto cotidiano es suficiente para contaminar cualquier objeto que entre en contacto con ellas.

Otros autores, investigadores de la Universidad de Aston, publicaron en el 2014 un comunicado de prensa titulado «Researchers prove the five-second rule is real. Aston University, Birmingham, United Kingdom», donde informaban que el tiempo de contacto afectó significativamente a la transferencia de superficies contaminadas 
(previamente inoculadas) con E. coli y Staphylococcus aureus, (alfombra, laminado y baldosa) a los alimentos (tostadas, pasta, galletas y un dulce pegajoso), pero indicaba que la transferencia era tan pequeña que podría considerarse como poco peligrosa (Miranda y Schaffner 2016). El primer artículo publicado en una revista con revisión por pares sobre el tema fue un estudio realizado sobre la transferencia de Salmonella enterica serovar Typhimurium desde diferentes superficies previamente esterilizadas e inoculadas por esta bacteria en una concentración de $10^{8}$ UFC por superficie (Dawson, Han, Cox, Black y Simmons 2007). Estos autores mostraron que, en tiempos de contacto más largos $(5,30$ y 60 segundos), aumentó la transferencia de Salmonella enterica serovar Typhimurium de madera, baldosa o alfombra a distintos alimentos, pero solo 8 horas después de la inoculación de la superficie, lo que implicaba la necesidad de una adecuación previa de la bacteria al sitio de inoculación.

Por otro lado, más recientemente, y teniendo en cuenta los estudios anteriores, Miranda y Schaffner (2016) realizaron un estudio más completo usando la bacteria no patógena Enterobacter aerogenes y utilizaron la bacteria inoculada en diferentes superficies de distintas características, todas ellas superficies potencialmente presentes en un ambiente doméstico (alfombras, madera, acero inoxidable o baldosas de distintas características). Los alimentos usados para demostrar la transferencia desde las superficies antes nombradas fueron pan, pan con mantequilla, sandía y caramelos. La transferencia se realizó después de 5 horas de inoculación de las superficies que previamente se habían desinfectado, teniendo una concentración de $10^{7}$ unidades formadoras de colonias (UFC) por superficie $\left(16 \mathrm{~cm}^{2}\right)$. Los resultados mostraron que el tiempo de transferencia menor era igual a $1 \mathrm{~s}$, que las cantidades de bacteria transferida aumentaban con el tiempo de exposición y llegaban a la saturación en un momento determinado a partir del cual ya no aumentaban y que la velocidad y la cantidad de bacterias transferidas dependían tanto del alimento como de la superficie inoculada.

Atendiendo a la bibliografía consultada se puede afirmar que la R5S no es correcta, ya que no determina el tipo de suelo sobre el que se deja caer la comida ni la naturaleza del propio alimento. No obstante, puesto que todos los estudios previos se han realizado en base a una superficie previamente desinfectada y posteriormente inoculada con una única especie bacteriana a altas concentraciones $\left(10^{7}-10^{8}\right)$, consideramos que esta situación está lejos de la realidad, puesto que pensamos que en una superficie inoculada de forma natural convivirán distintas especies y probablemente en concentraciones menores a las inoculadas, lo cual podría dar unos resultados totalmente distintos. Por tanto, este trabajo pretende hacer un estudio simulando una situación más real con el objetivo de poder demostrar si el medio de cultivo podría contaminarse en tiempos cortos y llevar a cabo una concienciación sobre la contaminación de las superficies y su relación con el alimento.

El objetivo primario de este estudio es observar y analizar de forma preliminar el grado de contaminación que obtienen varias muestras de medios de cultivo en distintos tipos de suelo a medida que transcurre el tiempo, con la intención de verificar o rechazar la hipótesis generada por la creencia popular de la regla de los cinco segundos.

\section{Método}

Para realizar este estudio, se han recogido 24 muestras en placas Petri con medio de cultivo Nutrient Agar. El medio de cultivo Nutrient Agar o agar nutritivo es un medio utilizado para el cultivo de un amplio rango de especies bacterianas. Para ello, con 
ayuda de un bisturí estéril, se despega el medio de la placa, manteniéndolo siempre en condiciones estériles hasta el momento del muestreo.

Los muestreos se realizaron en dos tipos de suelo, el suelo del laboratorio de microbiología (considerado como limpio) y el del pasillo de la Escuela Superior de Tecnología y Ciencias Experimentales de la Universitat Jaume I, considerado como más contaminado, ya que el número de personas que lo pisan es muy superior al del laboratorio. La muestra se recogió manteniendo en contacto con el suelo el medio durante dos tiempos: uno más corto, de 1 segundo, y otro más largo, de 4 segundos, en ambas superficies. Una vez pasado el tiempo, con ayuda de pinzas estériles se devolvía el medio a la placa. Todos los cultivos se han incubado durante dos días a $27^{\circ} \mathrm{C}$.

Tras el periodo de incubación, se ha realizado un recuento de las unidades formadoras de colonias (UFC) y de los distintos tipos de colonias microbianas halladas en el medio de cultivo. A continuación, se ha llevado a cabo un análisis estadístico de los datos calculando el promedio y error estándar.

Respecto a las variables empleadas en el estudio, encontramos:

- Variables dependientes: UFC y número de colonias diferentes formadas.

- Variables independientes: tiempo de contacto con el suelo y tipo de suelo.

El análisis estadístico se ha realizado aplicando un ANOVA para cada una de las dos variables independientes, usando el programa Statgraphycs-plus software para Windows V.5 (Statistical Graphycs Corp., MD, EE. UU.).

\section{Resultados}

Se han realizado cultivos de suelos de diferentes localizaciones, dejando la superficie de las placas en contacto con el suelo en dos tiempos: uno muy corto (1 segundo) y otro más largo (4 segundos). Los resultados obtenidos en el estudio de la variedad cuantitativa y cualitativa de microorganismos en los suelos deL laboratorio y del pasillo se muestran en la figura 1.

El análisis del número de UFC en cada placa (figura 1.A) mostró que las muestras tomadas en 1 segundo contenían menor número de colonias que las que estuvieron expuestas más tiempo, no presentando diferencias entre las que provenían del laboratorio y del pasillo. En cambio, las muestras obtenidas en 4 segundos fueron significativamente mayores en ambos suelos y, además, distintas entre ellas, puesto que el mayor número de microorganismos se obtuvo en los cultivos cuyos medios estu vieron durante 4 segundos en suelo sucio (pasillo 4 s). 
A

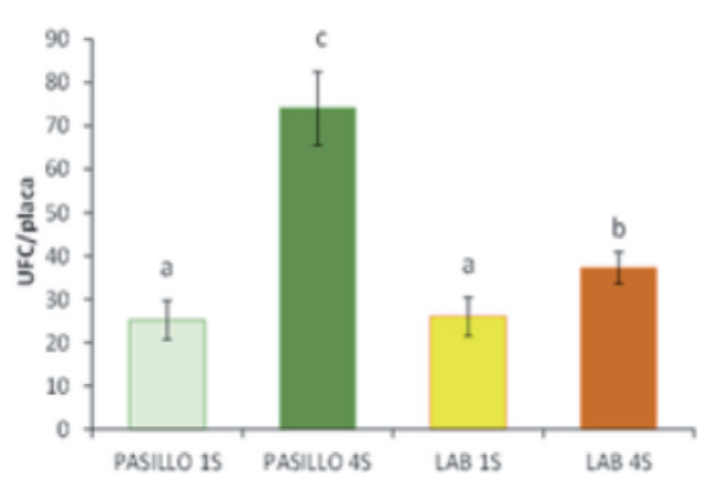

\section{B}

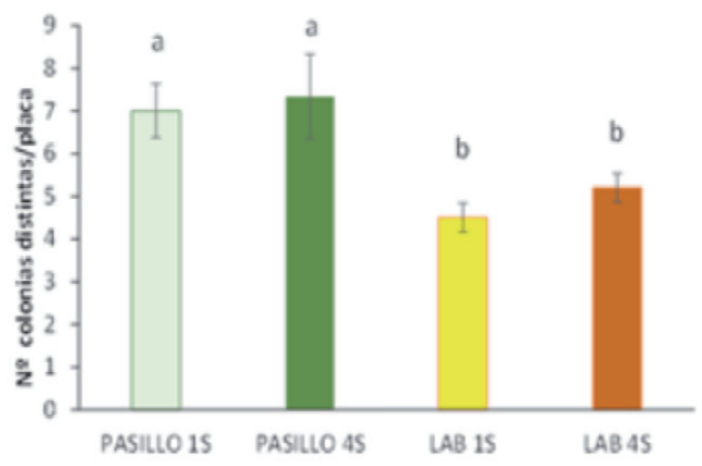

Figura 1. Resultados de los recuentos de las unidades formadoras de colonias (A) y del número de colonias distintas obtenidas en las muestras del pasillo y laboratorio después de 1 y 4 segundos de contacto del medio nutritivo con el suelo (B). Las barras representan el error estándar. Letras distintas significan diferencias significativas de acuerdo con el test LSD (procedimiento de diferencia mínima significativa), $\mathrm{P}<0,05$.

Respecto al estudio de la variabilidad (figura 1.B), se observó una mayor cantidad de colonias distintas en las muestras procedentes de suelo sucio, pudiéndose detectar hasta más de 8 morfologías diferentes, sin que hubiera diferencia en los tiempos de contacto (pasillo 1s y pasillo 4s). Tampoco se observaron diferencias entre la variedad de colonias entre las muestras del suelo limpio a distintos tiempos (lab 1s y lab 4s), siendo significativamente menor la variabilidad respecto a las del suelo sucio (alrededor de 5 colonias distintas). La figura 2 muestra la fotografía de dos placas representativas de cultivos a $4 \mathrm{~s}$.

En el caso del pasillo, con mayor variabilidad, no hubo un tipo de colonias predominante y se pudieron detectar diferencias tanto de estructura como de pigmentación (figura 2.A). En cambio, las colonias observadas en el laboratorio fueron morfológicamente distintas a las del pasillo, no se observaron tantas colonias pigmentadas (figura 2.B) y destacaron las colonias filamentosas de bacterias (figura 2.C).
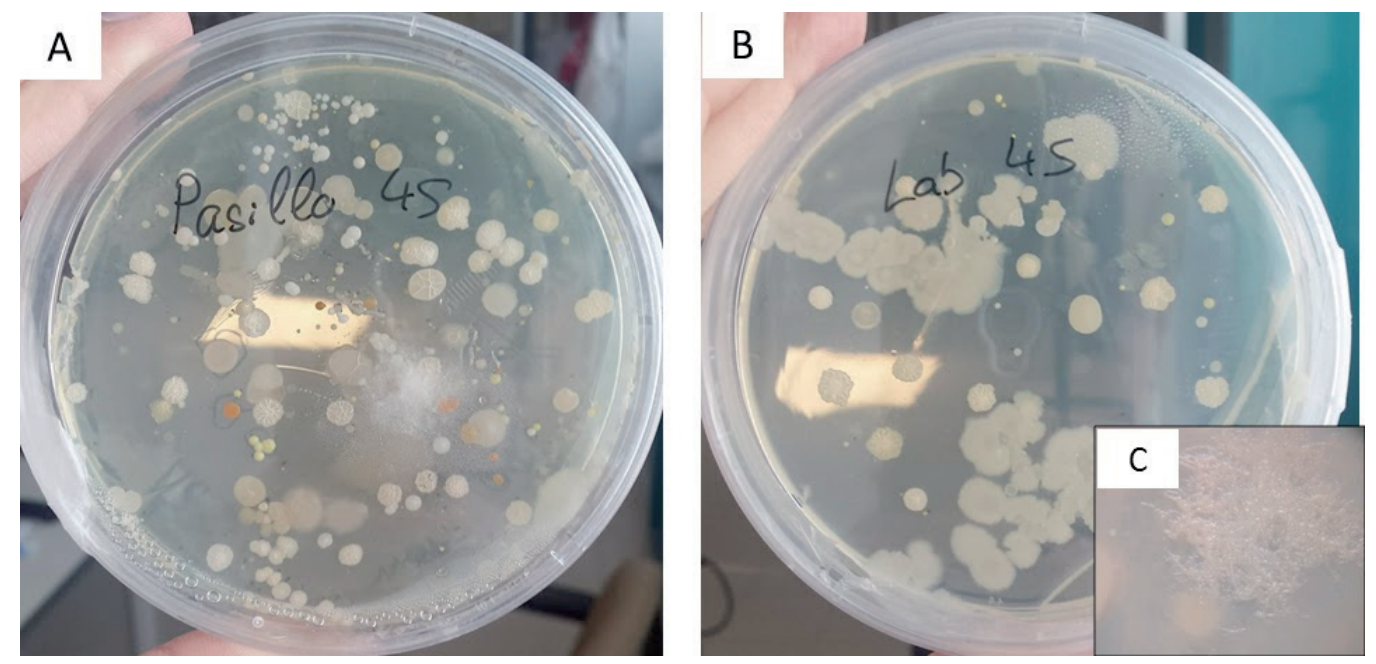

Figura 2. Placas representativas de los cultivos obtenidos en el pasillo (A) y el laboratorio (B). Detalle de una colonia filamentosa observada dentro del laboratorio (C). 


\section{Discusión y conclusiones}

Teniendo en cuenta la importancia de la educación en la prevención de las enfermedades, como futuros profesionales de enfermería nos propusimos demostrar si la creencia popular de la regla de los 5 segundos era verdadera o no, ya que hay constancia de que en nuestra sociedad es evidente la aceptación social de esta regla. Además, nos propusimos saber el tiempo mínimo que se podría considerar como necesario para que la transmisión de microorganismos del suelo al medio de muestreo fuera eficaz.

Se ha probado como tiempo mínimo 1 segundo, ya que un tiempo inferior es difícil que se dé mientras se cae la muestra y se recoge.

La revisión bibliográfica permitió comprobar que se han realizado trabajos diferentes en los que se inoculan cantidades determinadas de una especie determinada de bacteria $(E$. coli, Salmonella enterica serovar Typhimurium, Staphylococcus aureus, Enterobacter aerogenes) en distintas superficies previamente desinfectadas. El objetivo de todos estos trabajos era comprobar cómo se transmitían estas bacterias a superficies de alimentos 0 de objetos que entraban en contacto en las superficies inoculadas (Dawson, Han, Cox, Black y Simmons 2007; Pérez-Rodríguez, Valero, Carrasco, García y Zurera-Cosano 2008; Lunden, Miettinen, Autio y Korkeala 2000).

Los experimentos citados permitieron demostrar que la transferencia desde una superficie a un alimento se realizaba rápidamente y que tanto la rapidez de la transferencia como las cantidades transferidas dependían de la especie bacteriana, del inóculo inicial, del tiempo de exposición de la superficie inoculada, de las condiciones ambientales de la superficie y su topografía y del tipo de alimento. Pero en ninguno de ellos se refleja una situación real en la que la superficie de un alimento entra en contacto con otra superficie contaminada naturalmente. El hecho de que en los experimentos de mayor relieve científico se insista en la necesidad de dejar un tiempo a la bacteria en contacto con la superficie implica una necesidad de la bacteria para adecuarse y adherirse a ella (generalmente 5 o $8 \mathrm{~h}$ después de la inoculación en la superficie). Además, el hecho de que se inocularan grandes cantidades de una única especie se aleja de ser el reflejo de una situación normal. Consideramos que nuestro sistema es mucho más parecido a la realidad puesto que, como se sabe, en cualquier ecosistema microbiano natural las especies bacterianas que forman la comunidad compiten entre ellas. Muchas permanecen en forma esporulada y casi todas ellas, si el medio no es muy rico como sucede en medios semilimpios (suelo), donde las cantidades de materia orgánica no son muy abundantes, están presentes en concentraciones relativamente bajas.

Por tanto, la importancia del presente estudio es que, por primera vez, se comprueba si una superficie de naturaleza nutritiva, como es el medio Nutrient Agar, se pone en contacto con una superficie potencialmente contaminada, se producirá la transferencia incluso en un segundo de exposición.

A través de este estudio preliminar se puede afirmar que la regla de los 5 segundos no es cierta. Es importante destacar que, en todos los muestreos realizados, el número de UFC por placas era perfectamente reconocible en los tiempos de exposición, lo que implica que las densidades poblacionales eran inferiores a las usadas por Dawson, Han, Cox, Black y Simmons (2007) y Miranda y Schaffner (2016). Ello nos permitió hacer recuentos claros a través de los cuales se puede afirmar que el grado de contaminación del medio aumenta a mayor tiempo de exposición en ambos tipos de suelo, lo cual coincide con los resultados obtenidos previamente. El hecho de que haya un mayor número de colonias en las muestras expuestas a un tiempo más largo se podría deber a que las bacterias presentes en el suelo necesitan para poder adherirse al medio un tiempo que dependerá de la situación de la bacteria en el suelo, es decir, del tipo de superficie (si está en una zona 
menos accesible, en menor contacto con el medio), lo que coincidiría con lo observado por otros autores (Kusumaningrum, Riboldi, Hazeleger y Beumer 2003; Jensen, Friedrich, Harris, Danyluk y Schaffner 2013), más que al tipo de bacteria, ya que la variabilidad de las colonias permanece constante en cada medio en los diferentes intervalos de muestreo. No obstante, se observaron diferentes morfologías dependiendo del tipo del suelo, lo que indica que en ambas situaciones los microecosistemas eran distintos.

En este trabajo nos hemos centrado en averiguar cómo de rápida y eficiente sería la contaminación de un medio en contacto con una superficie como el suelo, ya que es la superficie donde más a menudo caen los alimentos. No hemos llegado a caracterizar el tipo de bacterias recogidas; además, el hecho de que las siembras se analizaran a $27^{\circ} \mathrm{C}$ fue porque tampoco nos centramos solo en patógenos, si no que el objetivo fue recoger la microbiota que pudiera estar presente (algunos de ellos potencialmente patógenos). Como era de esperar, se ha demostrado que la variabilidad de microorganismos depende de las condiciones en las que se estén desarrollando. Para poder dilucidar de qué condiciones depende la mayor supervivencia y variabilidad de los microorganismos, futuros trabajos podrían complementar el presente estudiando las posibles condiciones intrínsecas y extrínsecas que pueden influir en estos tipos de contaminación, trabajos en los que ya se podrían hacer siembras diferenciales, a distintas temperaturas, y llegar a una caracterización de las especies más abundantes presentes en la microbiota de las superficies que se van a estudiar.

\section{Referencias bibliográficas}

Dawson, Paul L., Inyee Han, M. Cox, C. Black y L. Simmons. 2007. «Residence time and food contact time effects on transfer of Salmonella Typhimurium from tile, wood, and carpet: testing the five-second rule». Journal of Applied Microbiology, 102: 945-953.

Jensen, Dane A., Loretta M. Friedrich, Linda J. Harris, Michelle D. Danyluk y Donald W. Schaffner. 2013. "Quantifying transfer rates of Salmonella and Escherichia coli O157:H7 between fresh-cut produce and common kitchen surfaces». Journal of Food Protection, 76: 1530-1538.

Kluck, Chad. 2000. I Think Therefore I Am: A Collection of My Thoughts. New York: Vantage Press.

Kusumaningrum, Harsi Dewantari, G. Riboldi, W. C. Hazeleger y Rijkelt Beumer. 2003. "Survival of foodborne pathogens on stainless steel surfaces and cross contamination to foods». Journal of Food Protection, 67: 1892-1903.

Lunden, Janne, Maria K. Miettinen, Tiina Autio y Hannu Korkeala. 2000. «Persistent Listeria monocytogenes strains show enhanced adherence to food contact surface after short contact times». Journal of Food Protection, 63(9): 1204-1207.

Miranda, Robyn C. y Donald W. Schaffner. 2016. «Longer Contact Times Increase CrossContamination of Enterobacter aerogenes from Surfaces to Food». Applied and Environmental Microbiology, 82(21): 6490-6496.

Pérez-Rodríguez, Fernando, Antonio Valero, Elena Carrasco, R. M. García y Gonzalo Zurera-Cosano. 2008. "Understanding and modelling bacterial transfer to foods: a review». Trends in Food Science and Technology, 19(3): 131-144.

Picklesimer, Phyllis. 2003. «If You Drop It, Should You Eat It? Scientists Weigh In on the 5-Second Rule». ACES News, University of Illinois College of Agricultural, Consumer, and Environmental Sciences. Recuperado de: https://aces.illinois.edu/news/if-you-drop-it-should-you-eat-it-scientists-weigh-5second-rule 